\title{
Use Integrated Management of Childhood Illnesses guidelines: a need for adaptation for use in Ghindae Hospital, Eritrea
}

\author{
Abraham Kebedom MD'; Tadesse Teclebirhan MD'; Winta Beyene²; Jacob Mufunda', MD, Ph.D; \\ Andemariam Gebremicheal, Ph.D ${ }^{1}$ \\ ${ }^{1}$ Orotta School of Medicine \\ ${ }^{2}$ Ghindae Zonal Referral Hospital
}

Correspondence to be sent to: akebedom@yahoo.com

Orotta School of Medicine

P.O. BOX 10549, Asmara, Eritrea

Abstract

Background: Diarrheal diseases are among the commonest causes of morbidity and mortality among infants and young children in the developing world and most commonly in the sub-Saharan including Eritrea. Integrated Management of Childhood Illnesses (IMCI) is a strategy developed by UNICEF and WHO for developing countries and other resource poor countries currently being practiced in Africa, Asia, and South America.

$\mathrm{IMCl}$ guidelines are simplified system of diagnosis and treatment that is designed for use by health workers with limited training and little or no laboratory support. According to this guideline bloody diarrhea is treated with ORS, additional fluid support and cotrimoxazole empirically with the assumption that the etiologic agent is shigella. If the child does not improve on follow up then metronidazole is added with the assumption that the etiologic agent is parasitic mainly amoeba and giardia.

Objective: The objective of this study was to assess the use of $\mathrm{IMCl}$ guidelines in children presenting with diarrhea at Ghindae Hospital.

Methods: The study was a prospective in which all children below the age of 5 years, who presented primarily with all forms of diarrhea during the one month period from June $1^{\text {st }} 2008$ to June 302008 , were included in the study. All stool samples were subjected to laboratory analysis.

Results: Eighty seven children who presented with all forms of diarrhea to the IMCI OPD or as IPD were included in the study. More than $50 \%$ of the cases had parasitic infestation mainly Amoeba and Giardia. Less than $5 \%$ of the children presented with mild or severe dehydration. The majority (92\%) of the cases had no dehydration had diarrhea with no dehydration.

Conclusion: In Ghindae community there is a justification for use of metronidazole as a first line treatment of bloody diarrhea, because of the preponderance of parasitic infestation instead of bacterial causes for the majority of cases of children presenting with diarrhea, a clear need for adaptation of IMCI

\section{Introduction}

Integrated Management of Childhood Illnesses (IMCI) program focuses on major childhood illnesses which occur in children below five years. The major childhood illnesses that IMCI program focuses on are malnutrition, diarrhoea, pneumonia (acute respiratory infections), measles, and malaria. These five diseases account for over $70 \%$ of the 11.5 million deaths and 80 $90 \%$ sick child consultation in developing countries. The purpose of this program is to make a rapid approach for diagnosis and management of common childhood illnesses in resource limited countries. The basic IMCl course is designed to help the first level health workers acquire new skills to manage sick children cost effectively ${ }^{1,2}$.

$\mathrm{IMCl}$ is a strategy that was jointly developed by UNICEF and WHO based on successful intervention and management childhood diseases. It addresses the principal causes of infant and childhood morbidity and mortality in developing countries ${ }^{1}$. This intervention was introduced in 1995 and is currently being successfully implemented in more than hundred countries. These conditions often occur in combinations requiring a holistic approach of assessment, treatment, and caretaker counseling ${ }^{3,4}$. According to recent reports,
$\mathrm{IMCl}$ can contribute to $6.5 \%$ reduction in child mortality each year ${ }^{1}$.

The $\mathrm{IMCl}$ strategy combines improved case management of childhood illness in first-level health facilities with aspects of nutrition, immunization, disease prevention, and promotion of growth and development. There are three components to $\mathrm{IMCl}$ namely; improving the skills of health workers, improving the health system, and improving household and community practices, all of which encompass both curative and disease preventive/ health promotive activities ${ }^{2}$.

Every year about 12 million children die before they reach their fifth birthday, many of them during the first year of life. Seventy percent of these deaths are due to the diseases where the IMCI focuses on'. In Eritrea a study done in 2003 study showed that Infant Mortality rate was 48 per 1000 compared to 72 per 1000 in 1995 and Under 5 Mortality rate were 93 per 1000 compared to 136 per 1000 in 1995. The Ministry of Health of the State of Eritrea adopted the $\mathrm{IMCl}$ as a strategy to reduce deaths and frequency and severity of illness and to promote healthy growth and development in children under 5 years of in $2001 .^{5}$

Ghindae is a small town in the Northern Red Sea 
Zoba with a population of about 20,000 people ${ }^{5}$. The town lacks the basic solid waste and sewage management system. Moreover, it has a poor water supply system. According to statistical data from the hospital and from the residents, diarrheal diseases such as amoebiasis and gardiasis have been common since 2000. According to the data from Ghindae hospital for 2007 amoebiasis and giardiasis were respectively ranked fourth and sixth of the top diseases for the OPD under 1 year olds, fourth and fifth respectively among the OPD under 5 years of age, and ameobiasis registered fifth among the IPD under 1 year old. From this data it can be inferred that the burden of ameobiasis and giardiasis among children under 5 years of age is substantial ${ }^{5}$.

The objective of this study was to conduct a prospective study on the pattern of diarrheal diseases on the Ghindae community and assess the use of $\mathrm{IMCl}$ guidelines in patients presented with diarrhea at Ghindae Hospital.

\section{Methods}

The study was a prospective study in which all children under five years of age visiting to the $I \mathrm{MCl}$ OPD of Ghindae Hospital with diarrhea were included in the study. Children presenting with bloody and non bloody diarrhea had samples of the stool investigated and their results were recorded. Eighty seven children of age under 5 years who primarily presented with bloody and non bloody diarrhea were included for the study starting from June 1, 2008 to June 30,2008. This period was chosen because diarrheal diseases tend to increase when there is shortage of water during the dry season.

The inclusion criteria for the study were children who were under 5 years of age presenting primarily with diarrhoea to the IMCI OPD of Ghindae Hospital. Children presenting with similar signs and symptoms within 10 days of the initial visit were included as one case for the study, but if it was after 10 days the children were included for the study for the second time. Any patient presenting after completing treatment and remission of symptoms were considered as new cases.

\section{Results}

Eighty seven children aged $<5$ years were included in the study. Most of them 44 (50.57\%) were in the age range of $12-60$ months, whereas $38(43.67 \%)$ and 5 (5.74\%) were in the range of 6-12 months and less than 6 months old, respectively. Fifty three were males and 34 females. Of all the cases, $80.49 \%$ were from Ghindae whereas $19.54 \%$ were from outside Ghindae but from neighbouring areas such as Dongollo, Shieb, and Metkel Abiet. The cases were distributed as follows; 45 (51.7\%), 14(16.09\%) and 11(12.64\%) from administrative zones 1, 2 and 3, respectively.

In $49(55.17 \%)$ of the cases abdominal parasites were identified in their stool, whereas in the rest were negative (Figure 1). Eighty (91.95\%) had diarrhea with no dehydration, $3(3.44 \%)$ and $4(4.49 \%)$ had diarrhea with some and severe dehydration, respectively.

Twenty six children (29.88\%) had secondary diagnoses such as pneumonia, malnutrition and acute respiratory infection.

\begin{tabular}{|l|c|c|c|c|c|}
\hline \multicolumn{7}{|c|}{ Table 1: Results of Stool Examination } \\
\hline Age & $\begin{array}{l}\text { Entamoeba } \\
\text { hystolytica } \\
\text { trophozoite }\end{array}$ & $\begin{array}{l}\text { Giardia } \\
\text { lamblia } \\
\text { tropho } \\
\text { zoite }\end{array}$ & $\begin{array}{l}\text { Giardia +d } \\
\text { Entameoba } \\
\text { hytolytica }\end{array}$ & $\begin{array}{l}\text { Amoeba } \\
\text { +Giardia } \\
\text { +H. nana }\end{array}$ & $\begin{array}{l}\text { No } \\
\text { Abdo } \\
\text { minal } \\
\text { parasite } \\
\text { seen }\end{array}$ \\
\hline $\begin{array}{l}<6 \\
\text { month }\end{array}$ & 1 & 0 & 0 & 0 & 4 \\
\hline $\begin{array}{l}6-12 \\
\text { months }\end{array}$ & 11 & 4 & 1 & 3 & 19 \\
\hline $\begin{array}{l}12-60 \\
\text { months }\end{array}$ & 8 & 8 & 3 & 9 & 16 \\
\hline $\begin{array}{l}\text { Total } \\
\text { Perc } \\
\text { entage }\end{array}$ & 20 & $\begin{array}{c}12(13 . \\
7 \%\end{array}$ & $\begin{array}{c}4(4.5 \\
\%\end{array}$ & $\begin{array}{c}12(13.7 \\
\%\end{array}$ & 39 \\
\hline
\end{tabular}

\section{Discussion}

Diarrhoeal diseases are still continuing to be among the major cause of morbidity and mortality in children among the developing countries including Eritrea. Eighty seven children who presented with all forms of diarrhea to the IMCI OPD or as IPD were included in the study. More than $50 \%$ of the cases had parasitic infestation mainly Amoeba and Giardia. Less than $5 \%$ of the children presented with mild or severe dehydration. The majority (92\%) of the cases had diarrhea with no dehydration suggesting appropriate implementation of $\mathrm{IMCl}$ at the community level.

$\mathrm{IMCl}$ is a cost effective strategy targeted against common ailments afflicaiting children in resource poor countries. The targeted diseases are diarrhea, pyrexial illness and malnutrition the cumulative control of which will lead to the attainemtn of millennium development goal (MDG) 4. There community based and health facility based components of the strategy. This study focused at the management of diaarhea in Ghindae Hospital.

Recent evidence suggests that many improved drinking water supplies suffer from poor reliability ${ }^{\text {. }}$. Many studies have reported the results of interventions to reduce illness through improvements in drinking water, sanitation facilities, and hygiene practices in less developed countries ${ }^{8,9}$. Improvements in water disinfection and behaviour had a huge impact in reducing diarrhea diseases in a recent report ${ }^{10}$. The microbiological causes of diarrhea have diverse geoecological variation. Some studies have reported predominance of viruses such as rota virus while others have found bacteria such as slamonella, E. coli and shigella camplylobacter taking the lion's share of the causes, while others have found parasitic infestations.

In the management of diarrheal diseases according to the $I \mathrm{MCl}$ guideline there is no clear indication for stool examination. Bloody diarrhea in young children under 5 years old is presumed to be due to shigellosis and as a result affected children are empirically started 
on cotrimoxazole to which the shigella species are susceptible. In communities like Ghindae where amoebiasis and giardiasis are highly prevalent, it is prudent to conduct stool examination for children of under 5 years of age presenting with bloody diarrhea justifying use of metronidazole as a first line antibiotic treatment rather than cotrimoxazole. Since the prevalence of bloody diarrhea is common in this community, and the health workers perform stool examination, a practice outside the $\mathrm{IMCl}$ guidelines, for those children and accordingly the appropriate treatment (metronidazole) is givenParasitic infestation was the main water borne causative agent in our setting ${ }^{1-3}$.

In Ghindae Hospital any child presented with diarrhea to the IMCI OPD requested to do stool exam and accordingly the appropriate antibiotic is prescribed if there is a need. But there is a need to document official justify.

The predominance of giardiasis and amebiaisis in contradistinction to shigellosis calls upon a revion of the empirical antibitoc choice of cotrimoxamoxale as first choice. Intead, metronidazole should be the first line antibiotic after failure of conservative treatment.

\section{Conclusion and recommendations}

The study result showed that parasitic infections among infants and young children were very common in the Ghindae community compared to other studies that were done in Zimbabwe. It showed that most of the parasitic infestations cases were presented as non bloody diarrhea. More than two-third of the patients were exposed to metronidazole in which it is not the firstline of treatment for bloody diarrhea according to $\mathrm{IMCl}$ guideline. So ordering stool exam to all children who presented with diarrhea and prescribing metronidazole in the IMCI OPD of Ghindae Hospital is justification for as an IMCl adaptation in that community.

\section{References}

1. Bryce J, Victora CG; MCE-IMCI Technical Advisors. Ten methodological lessons from the multi-country evaluation of integrated Management of Childhood Illness. Health Policy Plan. 2005 Dec;20 Suppl 1:i94-i105.

2. Bryce J, Victora CG, Habicht JP, Vaughan JP, Black REThe multi-country evaluation of the integrated management of childhood illness strategy: lessons for the evaluation of public health interventions. Am J Public Health. 2004 Mar;94(3):406-15.

3. Huicho L, Dávila M, Campos M, Drasbek C, Bryce J, Victora CGScaling up integrated management of childhood illness to the national level: achievements and challenges in Peru. Health Policy Plan. 2005 Jan;20(1):14-24.

4. Mandomando IM, etal. Etiology of diarrhea in children younger than five years of age admitted in rural hospital of southern Mozambique. Am J Trop Me Hyg 2007; 76: 522-7.

5. Ghindae Hospital, Eritrea, HMIS and IDSR reports 20002007.

6. Ghindae town, Eritrea, Administrative reports 2006.

7. Hunter PR, Zmirou-Navier D, Hartemann P. Estimating the impact on health of poor reliability of drinking water interventions in developing countries. Sci Total Environ. 2009 Apr 1;407(8):2621-4. Epub 2009 Feb 4

8. Fewtrell L, Kaufmann RB, Kay D, Enanoria W, Haller L, Colford JM JrWater, sanitation, and hygiene interventions to reduce diarrhoea in less developed countries: a systematic review and meta-analysis. Lancet Infect Dis. 2005 Jan;5(1):42-52.

9. Fewtrell L, Colford JM Jr. Water, sanitation and hygiene in developing countries: interventions and diarrhoea--a review. Water Sci Technol. 2005;52(8):133-42

10. MintzE, Bartram J, Lochery P,Wegelin M. Not justa drop in the bucket: expanding access to point-of-use water treatment systems. Am J Public Health. 2001 Oct;91(10):1565-70. 